\title{
The Contribution of Arm Muscle Strength and Coordination of Hand Eye Towards Chest Pass Skills in Self Development Activities of Basketball
}

\author{
Andi Lesmana Putra*
}

Faculty of Sport Science, Universitas Negeri Padang, Indonesia

${ }^{*}$ Corresponding author.Email: als.crew@yahoo.com

\begin{abstract}
The problem of this study was the lack of basket ball chest pass ability in at SMA Pembangunan Laboratorium UNP. This study aims to determine the contribution of arm muscle strength and hand-eye coordination towards chest pass skills. This research was a correlational study. The population in this study was students of SMA Pembangunan Laboratorium UNP who participated in basketball self-development activities as many as 39 students. The sampling technique used was purposive sampling technique, so that there was 30 students as the sample. The research data was obtained by a pull and push dynamometer test to measure arm muscle strength, ballwerfen und-fungen test to measure hand-eye coordination and wallbounce tests to measure chest pass. The data obtained were processed with simple correlation analysis techniques using applications of Microsoft Excel and multiple correlation analysis using the SPSS program version 16.00. The results of the study stated that: (1) from the statistical analysis performed obtained $r$ count $>r$ table $=0.37>0.36$. This means that there is a significant contribution between arm muscle strength $\left(\mathrm{X}_{1}\right)$ and chest pass skills ( $\mathrm{Y}$ ), and $\mathrm{X}_{1}$ contributes to $\mathrm{Y}$ by $14 \%$. (2) From the statistical analysis carried out obtained $\mathrm{r}$ count $>\mathrm{r}$ table $=0.40>0.36$. This means that there is a significant contribution between hand-eye coordination $\left(\mathrm{X}_{2}\right)$ and chest pass skills $(\mathrm{Y})$, and $\mathrm{X}_{2}$ contributes to $\mathrm{Y}$ by $16 \%$. (3) From the statistical analysis carried out obtained $\mathrm{f}$ count $>\mathrm{f}$ table $=4.511>3.35$. This means that there is a significant contribution between arm muscle strength $\left(\mathrm{X}_{1}\right)$ and hand-eye coordination $\left(\mathrm{X}_{2}\right)$ together with chest pass skills $(\mathrm{Y})$ and $\mathrm{X}_{1}, \mathrm{X}_{2}$ contributes to $\mathrm{Y}$ by $25 \%$.
\end{abstract}

\section{Keywords: Arm muscle strength, hand-eye coordination, chest pass}

\section{INTRODUCTION}

With the advancement of science and technology, many sports experts find new discoveries, both in terms of sports theories, techniques training as well as in the discovery of sophisticated equipment that is very supportive for improving sports performance.

In school, there are two programs, namely intracurricular and extracurricular (self-development) which are carried out in accordance with curriculum guidelines. The self-development program is carried out outside school hours, but the effect is very large on intracurricular activities. "Self-development activities aim to provide opportunities for students to develop and express themselves according to the needs, talents, and interests of students according to school conditions".[1]

Given how big the benefits of self-development if activities can be carried out properly from students can achieve maximum achievement, one of the most popular sports branches or many devotees for self-development is basketball. The aim of the basketball game is to put the ball into your opponent's basketball as much as possible and try to prevent your opponent from entering the ball into our basketball to win.

A complete basketball game is a team game with five players combining basic techniques to move the ball effectively. There are 3 basic techniques to move the ball in basketball games, namely dribbling, passing and shooting. Passing movements that are often used in matches are useful for managing attacks. "Passing is the first basic technique, with operands the players can move towards the basketball hoop for later shots"[2]. As for the types of passing, "chest pass, bounce pass, one-handed bounce pass, baseball pass, overhead pass, handhand-off pass, lob pass"[3]. "chest pass is the most common and most widely used operand in basketball games"[4]. To master basic chest pass skills, there are factors that affect chest pass. These factors include arm muscle strength, eye coordination, concentration, accuracy, endurance and speed. 
Arm muscle strength and hand-eye coordination is one of the factors influencing the success of the chest pass. Arm muscle strength is the ability of the hand muscles to be able to make strong and maximum movements. While eye-hand coordination is the ability to complete motorized tasks quickly and directed as determined by the movement control process which is integrated quickly and directed effectively and efficiently.

One of the schools that organize basketball selfdevelopment activities is the SMA Pembangunan Laboratorium UNP. This school is also famous for the achievements of its basketball team which was formed in self-development activities. This basketball team often wins various championships both between schools and between regions. Evidenced in the championship held by the Directorate General of Tax of the West Sumatra and Jambi Regional Offices in 2009, This School won the second place and in the PB Cup High School Development Championship won first place. In fact, around 50\%-60\% of players in the West Sumatra PORPROV Team were taken from high school teams and alumni of SMA Pembangunan Laboratorium UNP. But, in recent years SMA Pembangunan Laboratorium UNP experienced a decline in achievement. It is proved by the absence of this school in various championship events at both school and regional levels. It is a difficult job for coaches and players to take part in various basketball championships.

Based on observation results, the students chest pass ability was generally suspected to be unsatisfactory. This writer knows from the data on the results of learning the basic skills of self-development of high school basketball development which are of 39 students consisting of 25 men and 14 woman, there are only 9 students or $(23.08 \%)$ who get good grades, while 30 students or $(76.92 \%)$ get poor grades.

The low learning outcomes of the basic skills of basketball self-development are thought to be inseparable from the failures that occur when doing chest passes to a teammate where chest passes are preferred in the purpose of the attack. Among the mistakes, slow players doing chest passes, the weakness of the ball given so that the ball is not on target, does not reach friends and can be captured by opponents. Therefore, researchers are interested in researching and discussing this issue with the title "Contribution of Arm Muscle Strength and Hand-Eye Coordination in Chest Pass Skills Basketball SelfDevelopment Activities for High School Students in SMA Pembangunan Laboratorium UNP".

\section{METHODS}

This study used the type of correlational research that is ex-post facto. The population in this study amounted to 39 people, consisting of 25 men and 14 women. The samples in this study were 30 students, consisting of 20 men and 10 women; sampling in this study was carried out by purposive sampling technique. The data was collected by using the pull and push dynamometer test which aims to measure the strength of the arm muscles, while the ballwerfen und-fungen test (ball catch to the wall) aims to measure the coordination of the hand-eye and wall bounce to measure the ability of chest pass. The techniques of data analysis used simple and multiple correlations.

\section{RESULTS AND DISCUSSION}

\subsection{Results}

The results of data analysis carried out using the correlational formula are ex-post facto. The results of data analysis were carried out using simple and multiple correlation tests. From the results of a simple correlation test, $\mathrm{X} 1$ to $\mathrm{Y}$ using Microsoft Excel obtained $\mathrm{r}$ count> $\mathrm{r}$ table $=0.37>0.36$. This means that there is a significant relationship between arm muscle strength $\left(\mathrm{X}_{1}\right)$ and chest pass skills (Y). Furthermore, to determine the magnitude of the relationship between arm muscle strength and chest pass skills first determine the coefficient of determination. By looking at the value of $r$ count $=0.373$ the coefficient of determination $\mathrm{X}^{2}=0.14$. Thus the contribution coefficient $(\mathrm{K})=\mathrm{X}^{2} \times 100 \%$, then $0.14 \times 100 \%=14 \%$. This means that the arm muscle strength contributes $14 \%$ to chest pass skills.

From the results of a simple correlation test, X2 against $\mathrm{Y}$ using Microsoft Excel obtained $\mathrm{r}$ count $>\mathrm{r}$ table $=0.40>$ 0.36 . This means that there is a significant relationship between hand-eye coordination (X2) and chest pass skills (Y). Next to determine the magnitude of the hand-eye coordination relationship with the skull chest pass first determine the coefficient of determination. By looking at the value of $r$ count $=0.40$, the coefficient of determination $\mathrm{X}^{2}=0.16$. Thus the contribution coefficient $(\mathrm{K})=\mathrm{X}^{2} \mathrm{x}$ $100 \%$, then $0.14 \times 100 \%=16 \%$. This means that the variable hand-eye coordination contributes $16 \%$ to chest pass skills.

Furthermore, from the results of multiple correlation tests between X1 and X2 against Y using the SPSS 16.0 application obtained $\mathrm{f}$ count $>\mathrm{f}$ table $=4.511>3.35$. This means that there is a significant contribution between arm muscle strength $\left(\mathrm{X}_{1}\right)$ and hand-eye coordination $\left(\mathrm{X}_{2}\right)$ together with chest pass skills $(\mathrm{Y})$ and $\mathrm{X}_{1}, \mathrm{X}_{2}$ contributes to $\mathrm{Y}$ by $25 \%$. So, the conclusion is that there is a significant contribution of arm muscle strength and handeye coordination together to chest pass skills in Basketball Self Development of High School Students in the SMA Pembangunan UNP.

\subsection{Discussion}

Referring to these findings, it can be concluded that there is a significant contribution between arm muscle strength and hand-eye coordination together with chest pass skills on Basketball Self-Development of High School Students in SMA Pembangunan UNP.

When doing a chest pass, the ball movements are influenced by the style. In doing so, encouragement is needed. The stronger the force or impulse is given, the stronger the motion of the object given force. According to "muscle strength can be defined as the ability of a muscle or a group of muscles to overcome obstacles" [5]. 
In doing a chest pass, what works is the force of the arm muscles so that the ball can move. This means that the better the arm muscle strength of a player, the faster the ball will move. In doing movements' chest pass, there are several groups of muscles and forms of movement in the elbow joint and wrist muscles. the group of elbow joints and the shape of elbow joint movements are:

"First, flexion and elbow extension that takes place in the humeri-ulnar artery and humeri-radialis on the transverse axis. The main driver for flexion is the brachial musculus, the biceps brachii musculus, the brachioradial musculus while the main movers for extension are the triceps brachii musculus. Then, pronation and supination of the forearm take place in the radioulnar articulation on the longitudinal axis. The main driver for pronation is the quadratus pronator musculus and the pronator muscle teres, while the main movers for supination are the supinator muscle and the biceps brachii musculus. Whereas the wrist muscle group and the shape of the movement are the first, the main movers for wrist flexion are the carpiradialis flexor muscle and the flexor carpi ulnaris muscle. The second, the main driver for wrist extension is the extensor carpi radials muscle and the extensor carpiulnaris muscle. Third, the main driver for abduction is the flexor muscle of the carpiradialis and the extensor muscles of the carpiradialis. Then the main driver for adduction is the flexor carpiulnaris muscle and the extensor carpiulnaris muscle. "[6].

In increasing chest pass skills, there are several forms of exercise to increase muscle strength. As for the muscles that play a major role in increasing arm muscle strength, muscle action and the form of exercise include. First, the deltoid musculus, the action lifts the arms upward over the front, side and back. The form of training is bent over lateral raise. The exercise can use a barbell and can use dumbbells. The implementation, both hands hold the dumbbell both legs are opened slightly, the body flexes forward, then lift the dumbbell towards the side of the body (lateral). The view is pointing forward, then back to its original position. This exercise is carried out repeatedly, the number of repetitions (reps) and the weight of the load rose, adjusted for the purpose of the exercise. Second, musculus biceps brachii, flex arm action, arm supination and humeral articulation flex. The form of training is arm curl. Execution, take the barbell and adjust the weight of the weight to be lifted with the ability of the muscles, with a standing position, both feet opened slightly, then lift the barbell up front with both hands bent (flexed) to the desired limit, then return to its original position. Third, musculus triceps brachii, the action is an extension of articulation (straightening of the arm). The form of training is push-ups. The implementation, the initial position is with his stomach, both hands bent at the side of the body, both legs straight back, looking straight ahead, then by pushing both hands down (floor), lift up until both hands are in a straight position, then by bending both hands, the body is lowered back to its original position. Then, musk travezeus, the action shrugs up. The form of training is the military press. Implementation, standing position with both hands holding the dumbbell positioned above the shoulder with both hands bent, and then pushes both hands up until the elbows are straight, then lower back to its original position.

These forms of exercise can improve arm muscle strength well because when doing chest pass arm muscle strength is very necessary because by having good arm muscle strength a basketball player can do a chest pass well too. This is because to be able to do the chest pass a good, the element of physical strength is very necessary because strength is one aspect that determines the good or bad results of chest pass basketball players. "Every appearance in exercise requires muscle strength in addition to other elements that are also needed, the speed of contraction of related muscles (slow muscle fibers and fast muscle fibers), the amount of load that is moved too, intra and extra muscle contractions, muscle length at the time of contraction and angle of joints" [7].

The level of hand-eye coordination that is owned will certainly be better if you do not ignore the factors that can affect the achievement of chest pass skills. The form of deep eye coordination training is to throw a tennis ball with your right hand, then catch it back with your left hand and vice versa. Coordination functions for someone to speed up mastery of techniques enrich tactics and improve mental readiness. Besides that coordination is useful to avoid injury. Likewise in the implementation of chest pass in basketball games, especially for high school basketball players. SMA Pembangunan Laboratorium UNP. When doing a chest pass, the dominant form of coordination needed is hand-eye coordination.

Another important factor that influences the success of a chest pass is coordination. "Coordination is a process of muscle cooperation that will produce a movement that is structured and directed, which aims to form the movements needed in the implementation of a technical skill" [6].

Coordination can also be said as a person's ability in combining several movements into a unified and harmonious unity of motion caused by a reciprocal relationship between the nervous system and the means of movement in controlling impulses from the workings of muscles for the implementation of a movement. The forms of coordination exercises include exercises with changes in speed and rhythm, exercises in changing field conditions and equipment (modifying training equipment), a combination of various games, exercises to develop reactions, running hurdles at certain times, exercises in front of the glass, balance exercises, exercises with your eyes closed, doing complex movements at the end of the exercise. Another example of a form of deep eye coordination exercise is throwing a tennis ball with your right hand, and then catching it back with your left hand and vice versa.

"someone's coordination is influenced by several factors. These factors include power thinking, Skills and accuracy of the five senses, motor experience and biomotor abilities ". The ability of one's coordination is limited by several factors including the regulation of the central and nervous nerves peripheral such as thinking power ones in solving complex motor problems and tactics, coordination of nerve, muscle and sensory work such as fatigue of the 
five sensory organs in analyzing motor and maintaining the balance of the rhythm of muscle contraction. Besides that, it is also limited by the level of development of biomotor abilities such as strength, speed, endurance and flexibility. someone's coordination is influenced by several factors. These factors include power thinking, skills and accuracy of the five senses, motor experience and biomotor abilities" [8].

Based on the results of the study it can be concluded that there is a significant influence between the dependent variables namely arm muscle strength (X1) and hand-eye coordination (X2) on the independent variable namely chest pass skills ( Y) in high school basketball players SMA Pembangunan Laboratorium UNP. Based on the findings stated above, it can be interpreted that the arm muscle strength and eye-hand coordination together contributed $25 \%$, while the remaining $75 \%$ of the ability chest pass basketball ball of self-development students of Padang State University High School Development was influenced by other variables such as concentration, accuracy, endurance and speed.

Arm muscle strength is the ability of one's arm muscles to make maximum movements. While hand-eye coordination is the integration between the eyes as the main actor, and the hand as the function holder who performs a certain movement, in this case, both eyes will inform when the ball is in the dots so that the hand immediately swings to do the chest pass properly and correctly.

In basketball games, especially when doing chest pass, it is necessary to have good arm muscle strength and handeye coordination, if one of these two elements is not fulfilled, the chest pass that is done will not give the maximum result as desired when doing the chest pass. In addition to being able to do chest pass a good, the elements of the physical condition of arm muscle strength are needed, because strength is very influential in the implementation of chest pass and hand-eye coordination is needed so that movements that occur from information are integrated into the movement of the limbs so that all body movements must be controlled by sight and must be right, according to what the mind thinks.

From the explanation above, it can be concluded that arm muscle strength and hand-eye coordination are two important factors that can affect the skills of the chest pass a basketball player in high school. SMA Pembangunan Laboratorium UNP. Therefore, the ability of arm muscle strength and hand-eye coordination of high school basketball players The SMA Pembangunan Laboratorium UNP must be well trained to obtain chest pass skills maximum. If the arm muscle strength and hand-eye coordination of high school basketball players, the SMA Pembangunan Laboratorium UNP is good, then the chest pass skills produced by high school basketball players in the SMA Pembangunan Laboratorium UNP will be as expected. Arm muscle strength and hand-eye coordination are important factors in carrying out chest passes in basketball games, so these two factors must be considered by basketball coaches at SMA High School SMA
Pembangunan Laboratorium UNP so that the dreamed achievements can be achieved.

\section{CONCLUSION AND SUGGESTION}

Based on the results of the research that the author has described previously, it can be concluded as follows:

1. The results of the study prove that there is a significant relationship between arm muscle strength chest pass skills with a contribution coefficient level of $14 \%$.

2. The results of the study prove that there is a significant relationship of hand-eye coordination towards chest pass skills with a contribution coefficient level of $16 \%$.

3. The results of the study prove that there is a significant contribution of arm muscle strength and hand-eye coordination together to chest pass skills with a contribution coefficient level of $25 \%$.

Based on the above conclusions, the researcher can propose a number of suggestions for the good in the future that high school basketball players will do SMA Pembangunan Laboratorium UNP, as follows: The

1. Coach is expected to increase arm muscle strength and hand-eye coordination of high school basketball players. Chests pass correctly.

2. It is recommended to the coach to be able to arrange an exercise program according to the intensity, volume and purpose of the exercise that is able to increase the strength of the player, especially arm muscle strength and hand-eye coordination because it is the dominant ability used when doing chest passes.

3. For high school basketball players, the construction of the SMA Pembangunan Laboratorium UNP to be even more active in training to improve performance in basketball.

4. To get the results of chest pass maximally, it is necessary to pay attention to several influencing factors, especially in this study, the arm muscle strength and hand-eye coordination have a role that can affect the ability of the chest pass to be produced.

5. The results of this study are expected to be one of the inputs and literature for the next researcher using a larger sample.

\section{REFERENCES}

[1] Mulyasa. "Kurikulum Tingkat Satuan Pendidikan". Bandung: PT Remaja Rosdkarya. 2012. pp.28

[2] Ahmadi. "Permainan Bolabasket". Surakarta: Era Intermedia. 2007. pp. 67.

[3] Lieberman. "Bola Basket Untuk Wanita". Jakarta: Grafindo Persada. 1997. pp. 37

[4] A. Fardi. "Bola Basket Dasar". Padang. FIK UNP. 1999. pp. 24

[5] Syafruddin. " Dasar-Dasar Kepelatihan Olahraga". Padang: FIK UNP. 1999. pp. 25

[6] H. Irawadi. 'Kondisi Fisik Dan Pengukurannya'. Padang. FIK UNP. 2011. pp. 43

[7] Bafiman. "Kinesiologi dan Biomekanika Olahraga". Padang: Sukabina Press. 2014. pp. 35 